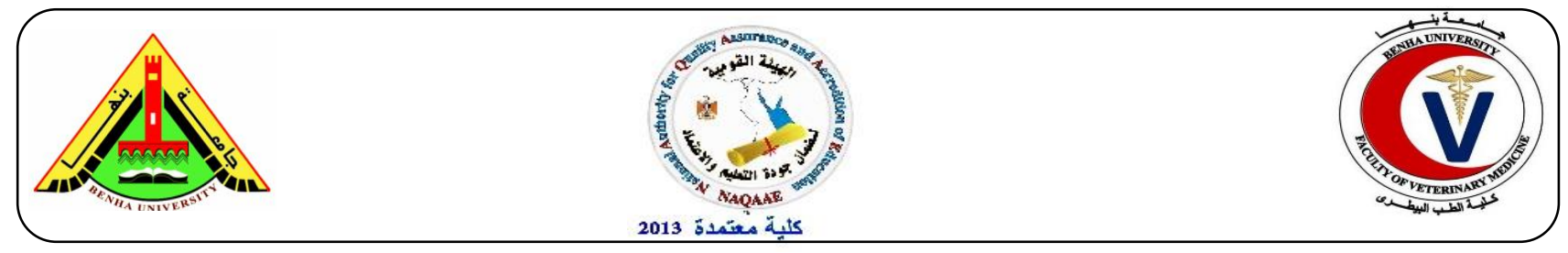

\title{
Clinical And Laboratory Studies On Equine Dermatophytosis
}

Mohamed H. Hamad ${ }^{a}$, Mohamed E. Mohamed ${ }^{\text {a }}$ Farouk A. El-Blkemy ${ }^{\text {a }}$ Nasser Z. Abouzeid ${ }^{\text {a }}$, Yasmine H. Tartor ${ }^{b}$

${ }^{a}$ Infectious Diseases, Department of Animal Medicine, Faculty of Veterinary Medicine, Zagazig University, Zagazig 44519, Egypt.

${ }^{b}$ Department of Microbiology, Faculty of Veterinary Medicine, Zagazig University, Zagazig 44519, Egypt.

\section{A B S T R A C T}

In this study out of 200 Arabian horses periodically clinically examined in a station for Arabian horses, Cairo, Egypt, 55 animals (27.5\%) had dermatological signs suggestive of dermatophytosis based on clinical examination. The majority of ringworm lesions were distributed over the head, neck, shoulder and limbs. Trichophyton mentagrophytes was the most commonly isolated dermatophyte species 19/39 (48.7 \%), followed by T. verrucosum (12/39, 30.7\%) and Microsporum canis $(8 / 39,20.9 \%)$. T. mentagrophytes and M. canis were isolated mostly from head and limbs. $T$. verrucosum was isolated from shoulder. The infection rate was higher in young horses less than one year old and increased during the winter season. Higher rate of infection was detected among female animals $(81.4 \%)$ than males $(60.7 \%)$. These findings have great veterinary and public health significance.

Key Words: Dermatophytosis, Arabian horse, Clinical diagnosis, Dermatophyte species, Risk factors.

(http://www.bvmj.bu.edu.eg) $\quad$ (BVMJ-36(1): 23-31, 2018)

\section{INTRODUCTION}

Dermatophytosis is a highly contagious fungal infection of keratinized tissues including hairs and skin, which cause significant destruction of the keratinized tissues and induce variable immunological responses. Dermatophytosis is of particular concern due to worldwide diffusion and zoonotic potential (Cafarchia et al., 2013).
Filamentous fungi of the genera Microsporum and Trichophyton (anamorphic state) and Arthroderma (teleomorphic state) cause animal dermatophytosis resulting in mild to severe, localized and/or diffuse infections (Chermette et al., 2008 and Mora-Montes and Lopes-Bezerra, 2017). Ringworm lesions had many adverse effects on horses. It can prevent the horses from working and interfere with 
their use in riding and racing purposes as horse with ringworm will not be welcome at shows or other events, so the coast value of diseased horses was decreased (El-Yazeed et al., 2013).

Several factors such as illness, poor nutrition, overcrowding, age, immunosuppression and stress predispose equine to infection (Abarca and Bragulat, 1997; Reed et al., 2004).

Isolation and identification of dermatophyte species are essential for understanding the source of infection and targeting preventive measures appropriately. Culture may also be necessary if the diagnosis is uncertain, or the infection is resistant to standard treatment (Brandt and Warnock, 2003).

Diagnosis of dermatophytes depends primarily on microscopical examination of skin scraping using $\mathrm{KOH} 20 \%$. It is the simplest and cheapest method (Panasiti et al., 2006). Microscopic examination of fungal elements in a clinical specimen is a rapid and inexpensive diagnostic test (Garg et al., 2009)

So, this study was directed to throw light on some aspects of ringworm affecting Arabian horses including isolation, identification of causative agents and determination of potential risk factors.

\section{MATERIAL AND METHODS}

\subsection{Animals}

A periodically and competent clinical history and physical and dermatologic examinations for a total of 200 horses less than one year up to 20 year old at horse station were examined clinically according to standard methods of Scott and Miller (2003) throughout the period of March 2017 to February 2018. A questionnaire was directed requesting on the number of infected contact animals, new imported animals, presence of stray dogs and cats in the same place, infected or suspected worker in the farm, site of infection, as well as pervious treatment, duration of lesion and its diameter.

\subsection{Samples and laboratory diagnosis}

Skin scrapings and hair samples were collected from edges of recent lesions of the infected animals after gently cleaning with gauze moistened in $70 \%$ alcohol for mycological examination. Hair was plucked from its root with forceps. These samples were placed in separate sterile Petri dishes and transported to the Department of Microbiology, Faculty of Veterinary Medicine, Zagazig University. Each sample was divided into two parts. The first part of samples was prepared for microscopical examination using $20 \%$ potassium hydroxide $(\mathrm{KOH})$ and the other for culture (Brandt and Warnock, 2003).

\subsection{Isolation and identification of dermatopyhtes}

A part from each sample was cultured on Sabouraud Dextrose Agar (SDA) slope with chloramphenicol $(0.005 \%)$

and cycloheximide $(0.04 \%)$. Then incubated at $30^{\circ} \mathrm{C}$ for two weeks and examined for growth every three days intervals. The identification of the dermatophyte species was achieved by macromorphological characteristics of the colonies on SDA as texture, growth rate, pigmentation, surface and reverse colour. Microscopical examination of culture using lactophenol cotton blue (LPCB) in terms of macroconidia was performed. Isolates were subcultured on Bromocresol Purple Milk Solid Glucose Agar media (BCP-MSGA) and observed for the growth rate and change of medium colour. The obtained data were compared and analysed according to Taha (2011). 


\section{RESULTS}

The clinical examination of 200 horses revealed that 55 animals $(27.5 \%)$ had focal circumscribed area of alopecia of about 1-5 $\mathrm{cm}$ in diameter, scaly with crusts of gray colour. Some focal areas coalesce and become more diffuse with intense formation of scaling and flaking. Lesions are usually not itchy. The dermatophytes lesions were distributed over 4 main regions of body as the following; head 21(38.1\%), neck 17 (30.9\%), shoulder 9 (16.3\%), limbs 8 (14.5\%) (Figure 1; A, B, C).

The higher rate of infection was found in female young animals ( $\leq 1$-year-old) mostly during winter months; also some other animals having infection during different seasons after had history of respiratory signs and diarrhea or exposed to malnutation (Table 1).

The direct microscopic examination of hair and scales from the affected horses $(n=55)$ revealed the presence of fungal spores in 43 $(83.6 \%)$ of samples (Figure 2). Dermatophyte isolates was detected in $39(70.9 \%)$ of the samples by mycological culture. On SDA agar, T. mentagrophytes colonies appear as powdery to granular, creamy colored on the surface and with brown to tan colour on reverse (Figure 3 A). While, T. verrucosum colonies appear as heaped slightly folded, and button or disk-shaped in appearance, and waxy with white to creamy colour surface and colourless revers (Figure $3 \mathrm{C}$ ) and $M$. canis colonies appear as fluffy with white surface and yellow to yellow-orange colour on reverse side (Figure $3 \mathrm{E}$ ).

Meanwhile, microscopic examination using LPCB stain revealed that $T$. mentagrophytes have elongated macroconidia (cigar shape) with thin wall, numerous small round microconidia singly or grape-like clusters and spiral hyphae are also present (Figure $3 \mathrm{~B}$ ). T. verrucosum have chains of thick walled chlamydospores (Figure 3 D) and M. canis have thick-walled spindle-shaped macroconidia with a terminal knob. A few pyriform to clavate microconidia with septated hyphae are also present (Figure $3 \mathrm{~F}$ ).

Dermatophyte species were isolated and identified from $39(70.9 \%)$ cases. As the following 19 (48.7\%), 12(30.7\%), 8 (20.5\%) cases infected with $T$. mentagrophytes, $T$. verrucosum and $M$. canis, respectively.

The recorded observation of dermatophytes species with relation to the site of infection was that $T$. mentagrophytes and M. canis were isolated mostly from head and limbs. $T$. verrucosum was isolated from shoulder (Figure 4). There was no mixed infection among the examined infected animals. 
Table (1): Frequency of horses had ringworm lesions at the study

\begin{tabular}{llll}
\hline Risk Factors & Category & Total No. & Positive (\%) \\
\hline \multirow{2}{*}{ Age } & $\leq 1$ year & 36 & $30(83.3)$ \\
& $>1$ year & 19 & $9(47.3)$ \\
Gender & Male & 28 & $17(60.7)$ \\
& Female & 27 & $22(81.4)$ \\
& Spring & 15 & $9(60.0)$ \\
& (Mar, Apr, May) & & $5(55.5)$ \\
Season & Summer & 9 & $8(66.6)$ \\
& (Jun, Jul, Aug) & & \\
& Autumn & 12 & $17(89.4)$ \\
& (Sep, Oct, Nov) & & \\
& Winter & 19 & \\
& (Dec, Jan, Feb) & & \\
\hline
\end{tabular}

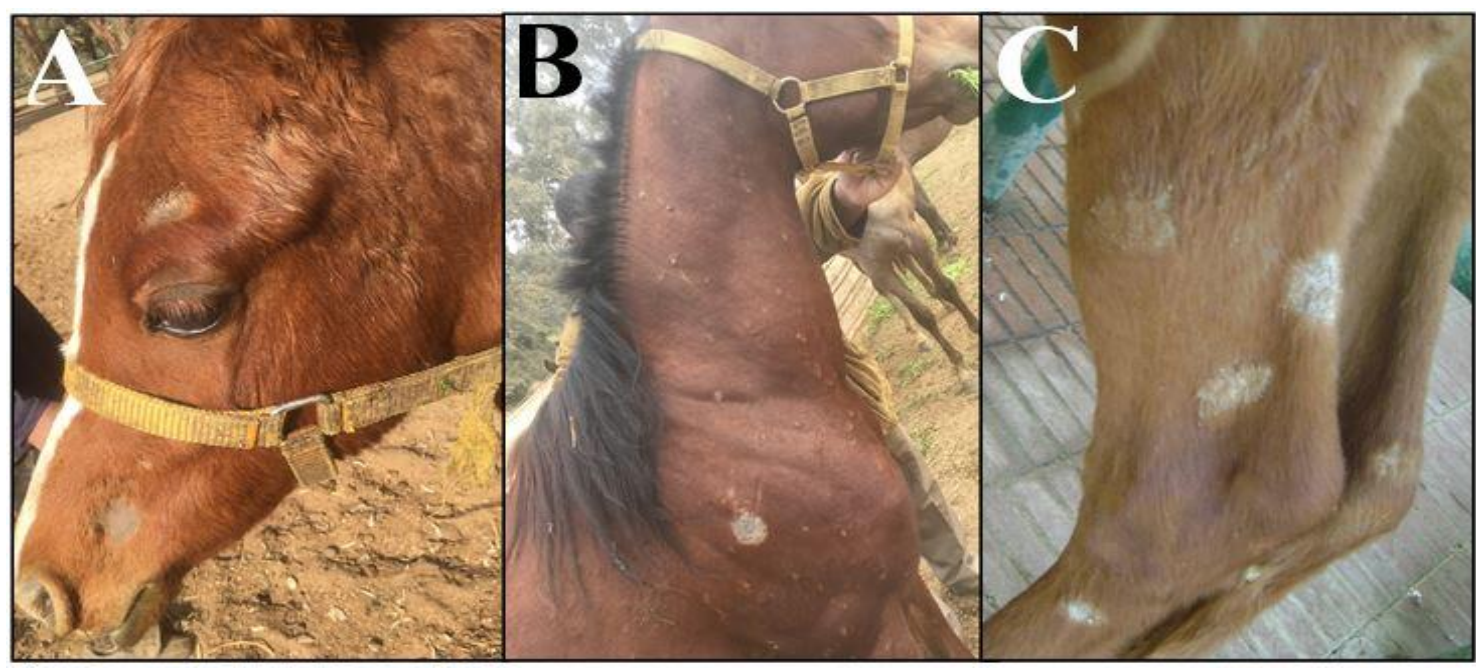

\section{Figure legends}

Figure 1: localized lesions of Arabian horse dermatophytosis on head (A), shoulder (B) and limb (C). 


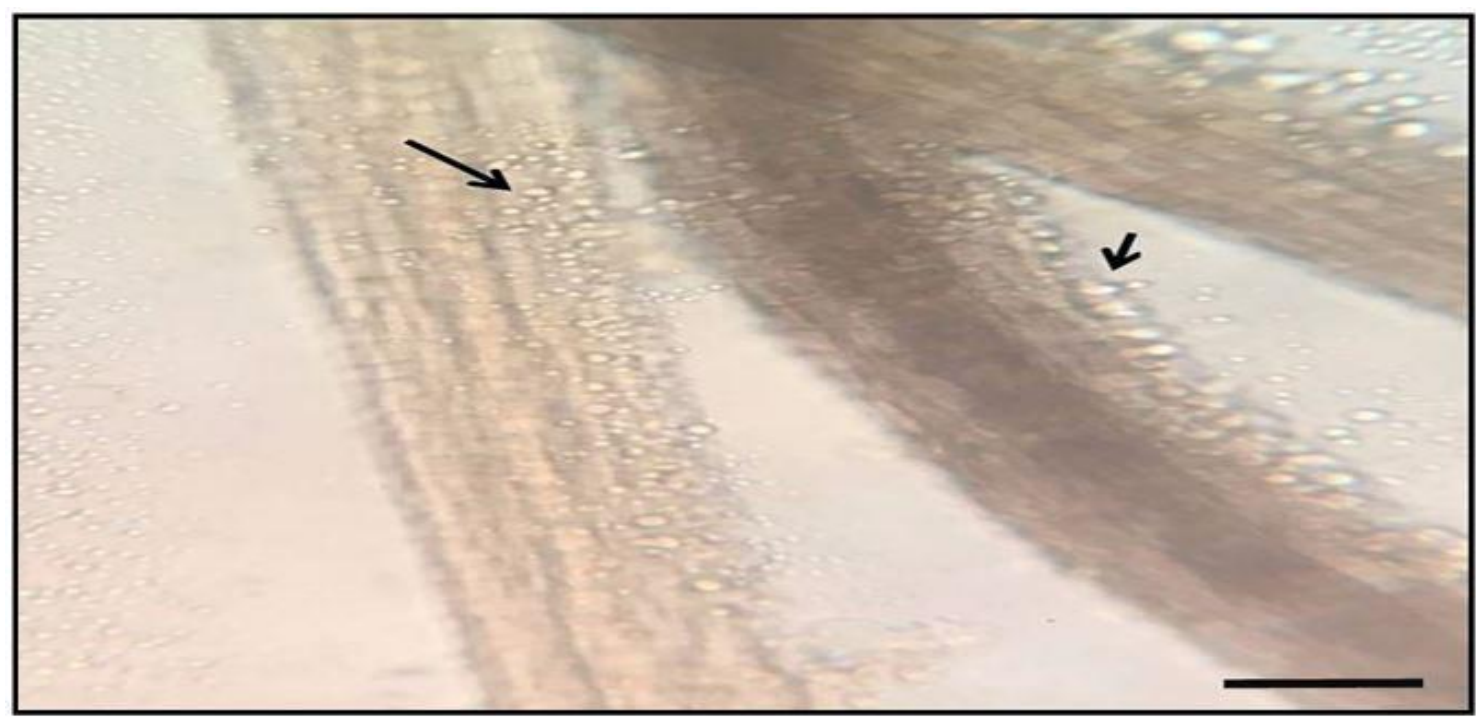

Figure 2: Direct microscopical examination of horse hair sample under light microscopy reveals ectothrix arthroconidia arranged in parallel rows on the hair filaments $(400 \times, \operatorname{Bar}=50 \mu \mathrm{m})$.

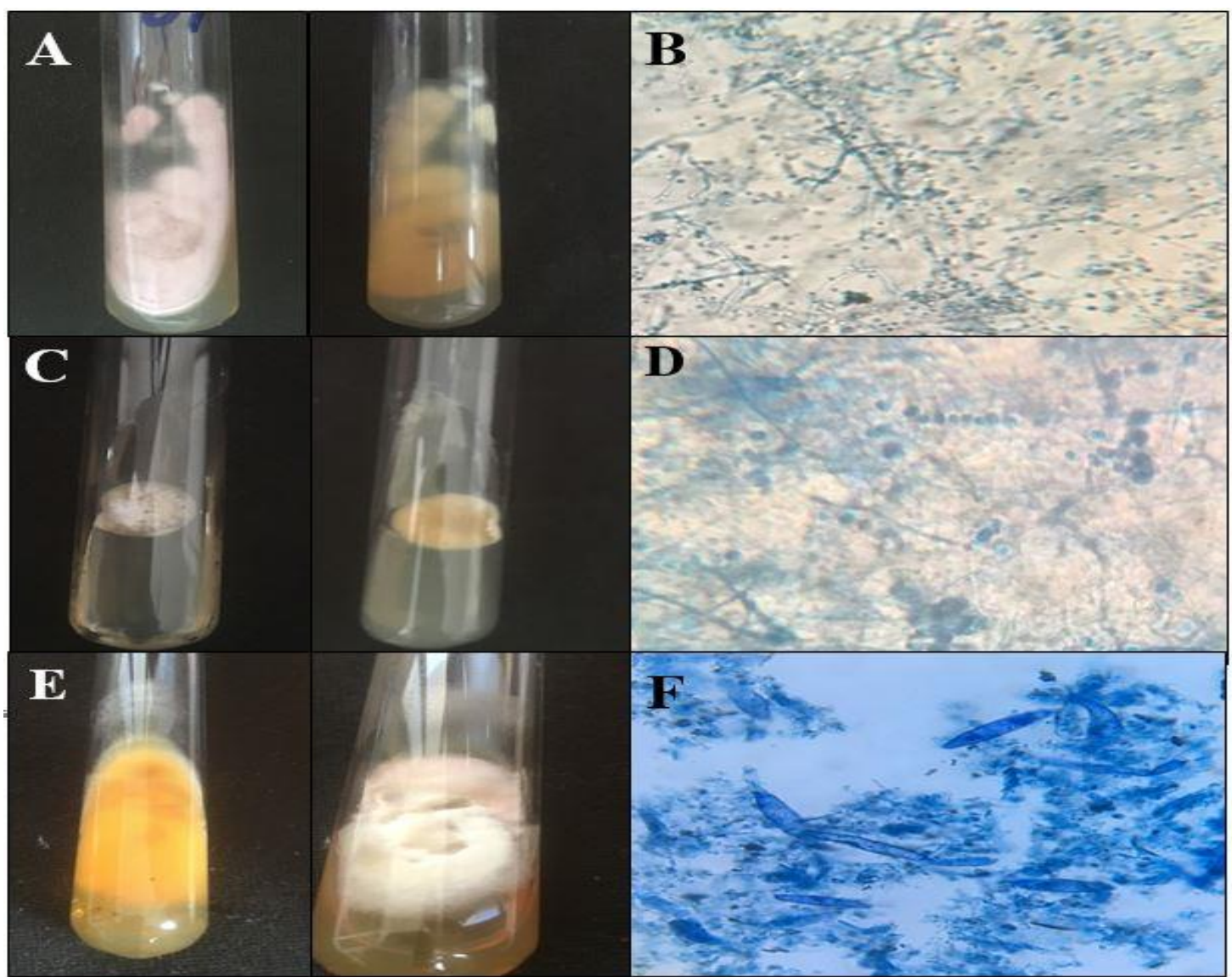

Figure 3: Macroscopic characters on SDA and microscopic examination with LCB staining for $T$. mentagrophytes $(\mathrm{A}, \mathrm{B})$, T. verrucosum $(\mathrm{C}, \mathrm{D})$ and $M$. canis $(\mathrm{E}, \mathrm{F})(400 \times$, Bar $=50 \mu \mathrm{m})$. 

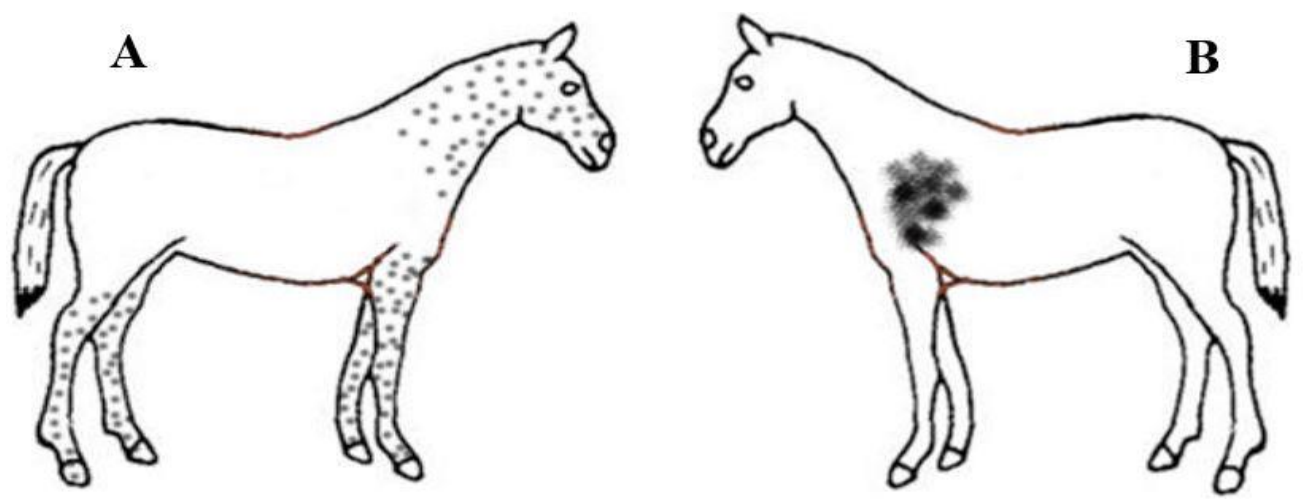

Figure 4: Areas of ringworm infection caused by T. mentagrophytes, $M$. canis (A) and $T$. verrucosum $(\mathrm{B})$.

\section{DISCUSSION:}

Dermatophytosis is a contagious fungal disease of animals and worldwide in distribution. Contagiousness among animal populations, cost of treatment, complexity of control measures, and the public health consequences of dermatophytosis explain their great importance (Chollet et al., 2015). In this study most common clinical signs observed among the infected horses was hair loss and dry and scaly skin in the affected areas. This finding agrees with result recorded by Rendle, (2018).

The overall percent of dermatophytosis among clinically infected Arabian horses was $27.5 \%$. This result is nearly similar to that reported in Nigeria (25\%) by Balogun et al., (2017) and in Egypt (35\%) by Tartor et al., (2016). While other studies reported much lower percentages among the clinically affected horses $3.8 \%$ and $16.8 \%$ in Egypt (ElYazeed et al., 2013, Ahdy et al., 2016) and $18 \%$ in Jordon (Al-Ani et al., 2002). Moreover, a higher prevalence $(68 \%)$ of dermatophytosis in Behera Governorate, Egypt was recently reported by Haggag et al., (2017). The proportion of positive samples in relation to the number of samples examined from cases of dermatophytosis varies considerably in different investigation. This could be attributed to that there are many risk factors playing important role in occurrence and spreading of dermatophytosis among horses such as climate, geographic locations and concentration of livestock, pets, or exotic animals present. Humid, warm, tropical, and subtropical areas appear to have higher incidence. Transmission of dermatophytes occurred by direct contact with infected hairs or animals; contaminated fomites or environment; or natural environment (Lockwood, 2013).

Table 1 revealed that dermatophytosis is usually more prevalent in young animals than old one. The risk of age was attributed to weak immunity and quantity and nature of the sebaceous glands in foal epidermis. The same result was reported previously (Stannard, 2000; Radostitis et al., 2007; Pereira et al., 2006 and Pilsworth and Knottenbelt, (2007) and Bond, (2010), who found that younger age was at high risk. Nevertheless, Yahyaei and Ebrahimi, (2000) declared that there was no significant difference between age groups and Haggag et al. (2017) found that most cases of equine ringworm were in old horses (6 years old). 
In this study, higher evidence for dermatophytosis was in winter coinciding with period of high humidity. This finding was in agreement with results obtained by previous authors (Lund and Deboer, 2008; Ahdy et al., 2010; Scott and Miller 2011 and Wagdy and Mohamed, 2016). This might be due to the suitable climatic conditions. However, Yahyaei and Ebrahimi (2000) suggested that the peak prevalence for equine dermatophytosis was in summer and Khosravi and Mahmoudi (2003) found no significant evidence for seasonal trend in the prevalence of dermatophytosis.

Fungal culture of affected hair and scale is the most reliable diagnostic test and is the only way to identify the specific dermatophyte (Sellon and Long et al., 2013 and White, 2009). Culture and subsequent species identification by microscopic examination is the current gold standard method but may take up to 4 weeks (Wisselink et al., 2011). The cases that were negative in culture could be due to previous antifungal treatment before sampling.

The detection of T. mentagrophytes, $M$. canis and $T$. verrucosum are consistent with those obtained by previous studies (Nweze, 2011, Maurice et al., 2016, Tartor et al., 2016 and Balogun et al., 2017). Therefore, the zoonotic aspect of infection transmission from horse to human is more likely with $T$. verrucosum and $M$. canis (Zukerman et al., 1992 and Romano et al., 2001). Human dermatophytosis when contracted from horses are most commonly seen on the legs (from bareback horse riding) or arms and is characterized by a pruritic, papulopustular dermatitis (Scott and Miller, 2003).
In the present study, higher incidence of infection was detected among female animals $(81.4 \%)$ than in males (60.7\%). Unlikely, Balogun et al., (2017)found that 12 out of 85 male horses (14.1\%) and 2 out of the 6 female horses $(33.3 \%)$ were positive. Another study reported that prevalence of dermatophytosis was higher in males (44\%) than (24\%) females (Haggag et al., 2017).

The majority of ringworm lesions were distributed over the head $(38.1 \%)$, neck $(30.9 \%)$, shoulder $(16.3 \%)$ and limbs $(14.5 \%)$. Descriptions of the disease in other study also cite dermatophyte lesion on the limbs (18.7\%), tail $(16 \%)$, head $(15 \%)$ and abdominal region (10\%) (Balogun et al., 2017).

Concerning with the finding of $T$. mentagrophytes and $M$. canis were isolated mostly from head and limbs. T. verrucosum was isolated from shoulder. Some authors have suggested that $M$. gypseum infections occur most commonly on the face, legs, and dorsal neck and rump, but not on the girth or saddle region. These sites of infections not reflect the dermatophyte species (Scott and Miller, 2003).

In conclusion these findings have great veterinary and public health significance.

\section{5.. REFERENCES}

Abarca, M. L., and Bragulat, M. R. (1997). Dermatophytes isolated from domestic animals in Barcelona, Spain. 137, 107113.

Ahdy, A. M., Sayed-Ahmed, M. Z., Younis, E. E., Baraka, H. N., and El-khodery, S. A. (2016). Prevalence and Potential Risk Factors of Dermatophytosis in Arabian Horses in Egypt. J. Equine Vet. Sci. 37, 
71-76. doi:10.1016/j.jevs.2015.12.008.

Al-Ani, F. K., Younes, F. A., and AlRawashdeh, O. F. (2002). Ringworm infection in cattle and horses in Jordan. Acta Vet. Brno 71, 55-60+155. doi:10.2754/avb200271010055.

Balogun, R. B., Jegede, H. O., Jibril, A., Kwanashie, C. N., and Kazeem, H. M. (2017). Prevalence and distribution of dermatophytes among domestic horses in Kwara state, Nigeria. Sokoto J. Vet. Sci. 15(2), 1-6. doi:10.4314/sokjvs.v15i2.1.

Bond, R. (2010). Superficial veterinary mycoses. Clin. Dermatol. 28, 226-236. doi:10.1016/j.clindermatol.2009.12.012.

Cafarchia, C., Aldo, B., Aldo, B., Otranto, D., and Aldo, B. (2013). Fungal diseases of horses. Vet. Microbiol. doi:10.1016/j.vetmic.2013.01.015.

Chermette, R., Ferreiro, L., and Guillot, J. (2008). Dermatophytoses in animals. Mycopathologia 166, 385-405. doi:10.1007/s11046-008-9102-7.

El-Yazeed, H. A., Effat, M., Abdalla, K., Bakry, M., Alarousy, R., and Farahat, E. (2013). Application of molecular techniques for rapid diagnosis of dermatophytes infection in horses. Glob. Vet. $\quad 10, \quad 310-317$. doi:10.5829/idosi.gv.2013.10.3.7275.

El Damaty, H. M., Tartor, Y. H., and Mahmmod, Y. S. (2017). Species Identification, Strain Differentiation, and Antifungal Susceptibility of Dermatophyte Species Isolated From Clinically Infected Arabian Horses. J. Equine Vet. Sci. 59, 26-33. doi:10.1016/j.jevs.2017.08.019.

Haggag, Y. N., Samaha, H. A., Nossair, M.
A., El, A., and Mohammad, R. M. H. (2017). Prevalence of Dermatophytosis in some animals and Human in Behera Province, Egypt. Alexandria J. Vet. Sci. 53, 64-71. doi:10.5455/ajvs.203688.

Khosravi, A. R., and Mahmoudi, M. (2003). Dermatophytes isolated from domestic animals in Iran. Mycoses 46, 222-225. doi:10.1046/j.1439-0507.2003.00868.x.

Lockhart, S. (2014). Laboratory Aspects of Medical Mycology. doi:10.1007/978-14419-6640-7.

Lockwood, S. (2013). American Association of Zoo Veterinarians Infectious Disease Committee Manual 2013 [Internet]. [cited 2014 October 28]. Available from http://www.aazv.org/resource/resmgr/ID M/IDM_Dermatophytosis_2013.pdf.

Lund, A., and Deboer, D. J. (2008). Immunoprophylaxis of dermatophytosis in animals. Mycopathologia 166, $407-$ 424. doi:10.1007/s11046-008-9111-6.

Mora-Montes, H. M., and Lopes-Bezerra, L. M. (2017). Current Progress in Medical Mycology. doi:10.1007/978-3-31964113-3.

Nweze, E. I. (2011). Dermatophytoses in domesticated animals. Rev. Inst. Med. Trop. Sao Paulo 53, 94-99. doi:10.1590/S0036-46652011000200007.

Panasiti, V., Borroni, R. G., Devirgiliis, V., Rossi, M., Fabbrizio, L., Masciangelo, R., et al. (2006). Comparison of diagnostic methods in the diagnosis of dermatomycoses and onychomycoses. 26-29.

Pereira, D. I. B., Oliveira, L. S. S. De, Bueno, A., Cavalheiro, A. S., Schwendler, S. E., Azevedo, M. I. De, et al. (2006). Surto de 
Trichophyton equinum var. equinum em eqüinos no sul do Brasil. Ciência Rural. St. Maria, 36(6), 1849-1853. doi:10.1590/S0103-84782006000600028.

Pilsworth, R. C., and Knottenbelt, D. (2007). Dermatophytosis (ringworm). Equine Vet. Educ. 19, 151-154. doi:10.2746/095777307X186929.

Radostitis, O. M., Gay, C. C., Hinchcliff, K. W., and Constable, P. D. (2007). Veterinary Medicine, 10th Edition,. El sevier, 1476-1478.

Reed, S.M., Bayly, W.M., Sellon, D.C. (2004) Equine internal medicine, 2nd edn. Saunders, St. Louis, Missouri.

Rendle, D. (2018). Dermatophytosis - “ Ringworm .’NADIS livestock health bulletins, 1-3.

Scott, D. W., and Miller, W. H. (2010). Equine dermatology. Elsevier Saunders, 536.

Scott, D. W., and Miller, W. H. (2011). Equine dermatology. 2nd ed.

Stannard, A. A. (2000). Alopecia in the horse an overview. Dermatology, Vet. 11, 191203.

Tartor, Y. H., El Damaty, H. M., and Mahmmod, Y. S. (2016). Diagnostic performance of molecular and conventional methods for identification of dermatophyte species from clinically infected Arabian horses in Egypt. Vet. Dermatol. 27. doi:10.1111/vde.12372.

Wagdy, R. E., and Mohamed, E. A. (2016). Identification of Different Dermatophytes Isolated From Cattle, Cats and Horses Suffered From Skin Lesions. Alexandria
J. Vet. Sci. 49(2), 126-132. doi:10.5455/ajvs.224778.

Yahyaei, M., and Ebrahimi, M. M. (2000). Survey on Horse Dermatophytosis in Golestan, Iran. Arch. Razi Inst. 51, 137141. doi:10.22092/ari.2000.109206.

Zukerman, I., Yeruham, I. and Hadani, A. (1992). An outbreak of ringworm (trichophytosis) in horses accompanied by human infection, Israel J. Vet. Med. 47:34-36. 